\section{Textbook and Color Atlas of}

\section{Traumatic Injuries to the Teeth}

Editors: Jens O. Andreasen, Frances M. Andreasen,

Lars Andersson

Publisher:Wiley-Blackwell, Oxford, UK

Language: English

ISBN: 978-1-119-16707-5

Edition: $5 / \mathrm{e}$

Year Published: 2018

Pages: 1064, illustrated

Price: $\$ 245.00$

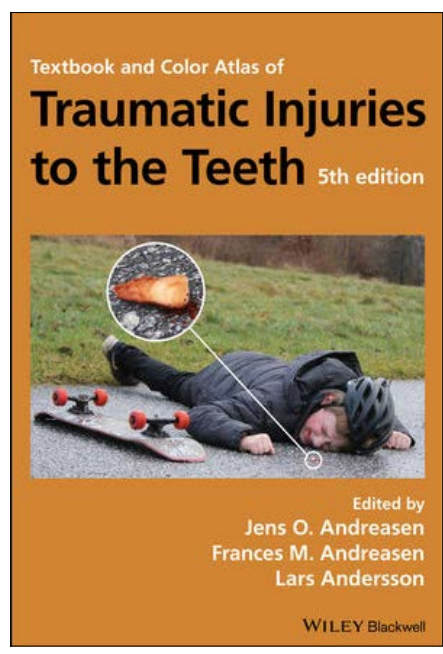

Marian-Vladimi

Constantinescu

DDS, MSc, PhD

Holistic Dental \& Medical Institute

of Bucharest-ROPOSTURO,

Bucharest, Romania

e-mail:

dr.vladimir.constantinescu@gmail.com

The $5^{\text {th }}$ edition of the book entitled "Textbook and Color Atlas of Traumatic Injuries to the Teeth" is an update of the issues presented in the previous 2007 edition; the book aims to present the dental traumatology from the perspective of an interdisciplinary treatment.

The book comprises 44 chapters, accompanied by several appendices and an index.

This book presents the nature of traumatic injuries, and then wound healing subsequent to injury, response of oral tissues to trauma, response of traumatized dental tissues to various treatment procedures and prediction and timing of healing complications.

The book tackles the characteristics of oral stem cells, the development of a bio-root and bone-resorbing osteoclasts with their role in dental tissue regeneration.

The psychological aspects of traumatic dental injuries and the different types of orofacial injuries in child physical abuse are presented, and then their classification, epidemiology and etiology are described.

Following the examination and diagnosis of dental injuries, we are informed about the different forms of traumatic injuries to the teeth, from coronary fractures, radicular fractures, dislocations, concussion and subluxation, extrusive and intrusive luxation, avulsion, injuries to the supporting bone and soft tissue, primary dentition and developing teeth.

The management of traumatic injuries to the teeth is exhaustively presented from regenerative endodontics, reinforcing endodontically, orthodontic treatment, restoration with resin composites, porcelain laminate veneers, conventional bridges, autotransplantation and implant therapy.

The restoration of the traumatized tooth is approached from several perspectives: biological, preventive and predicting the economic aspect.

Based on the experience of the Oral and Maxillofacial Surgery Department at the University Hospital in Copenhagen, Denmark, which has had over 4000 patients in more than 50 years, the Dental Trauma Guide has been complemented since 2006.

To promote best practices in dental traumatology, Scandinavian researchers have established the International Association of Dental Traumatology (IADT) and the journal Dental Traumatology.

The appendices provide us with a number of useful observation sheets, starting with an emergency record for acute dental trauma, a clinical examination form, a summary of treatment and a comparison between costs / effectiveness of different treatment solutions.

It is a comprehensive textbook, useful and necessary to undergraduate BDS, postgraduates in pediatric dentistry, oral surgery, endodontics, and general dentists that address dental trauma in a common effort to find the best treatment solutions for victims of dental trauma.

The Books Review is drafted in the reviewer's sole wording and illustrates his opinions. 